\title{
Mg-Containing Hydroxyapatite Coatings Produced by Plasma Electrolytic Oxidation of Titanium
}

\author{
César Augusto Antônio ${ }^{a, b *}$, Elidiane Cipriano Rangel ${ }^{a}$, Steven Frederick Durrant ${ }^{a}$, Adriana de \\ Oliveira Delgado-Silva ${ }^{c}$, Manfredo H. Tabacniks ${ }^{d}$, Nilson Cristino da Cruz ${ }^{a}$ \\ ${ }^{a}$ Laboratory of Technological Plasmas, Sorocaba Institute of Science and Technology, Paulista State \\ University - UNESP, Sorocaba, SP, Brazil \\ ${ }^{b}$ Sorocaba College of Technology, Sorocaba, SP, Brazil. \\ ${ }^{c}$ Federal University of São Carlos, Sorocaba, SP, Brazil. \\ ${ }^{d}$ Institute of Physics, University of São Paulo - USP, São Paulo, SP, Brazil.
}

Received: September 18, 2016; Revised: January 17, 2017; Accepted: February 12, 2017

\begin{abstract}
Plasma Electrolytic Oxidation (PEO) is promising for the processing of biomaterials because it enables the production of surfaces with adjustable composition and structure. In this work, aimed at the improvement of the bioactivity of titanium, PEO has been used to grow calcium phosphide coatings on titanium substrates. The effects of the addition of magnesium acetate to the electrolytes on the composition of the coatings produced during $120 \mathrm{~s}$ on Ti disks using bipolar voltage pulses and solutions of calcium and magnesium acetates and sodium glycerophosphate as electrolytes have been studied. Scanning electron microscopy, X-ray energy dispersive spectroscopy, Rutherford backscattering spectroscopy, X-ray diffractometry with Rietveld refinement and profilometry were used to characterize the modified samples. Coatings composed of nearly $50 \%$ of Mg-doped hydroxyapatite have been produced. In certain conditions up to $4 \% \mathrm{Mg}$ can be incorporated into the coating without any observable significant structural modifications of the hydroxyapatite.
\end{abstract}

Keywords: Plasma Electrolytic Oxidation, Mg-doped hydroxyapatite, titanium

\section{Introduction}

Owing to high biocompatibility, good corrosion and wear resistance, good mechanical properties, low density and chemical inertness, titanium and its alloys are widely used in the production of dental and orthopedic implants ${ }^{1,2}$.

Although titanium is biocompatible ${ }^{3,4}$, its intrinsic bioinertness does not stimulate spontaneous bone-implant integration ${ }^{5}$. To expand the successful applications as dental and orthopedic implants several methods are used to modify the titanium surface with the objective of improving its bioactivity. In this context, great improvement in biological properties, consequently reducing the rejection of implants ${ }^{6}$, has been achieved with calcium phosphate coatings.

Hydroxyapatite $\left(\mathrm{Ca}_{10}\left(\mathrm{PO}_{4}\right)_{6}(\mathrm{OH})_{2}\right)(\mathrm{HA})$ is a calcium phosphate that constitutes about $70 \%$ in weight of human bones. HA is a natural mineral that has excellent biological properties. When it is synthetically produced on the surface of titanium, it can promote bioactivity and improve the connection with bone tissue ${ }^{7}$. Nowadays it is possible to produce synthetic HA with similar characteristics to those of human bone, including bioactivity and biocompatibility, that can be used in biomedical applications ${ }^{8,9}$.

* e-mail: cesar.augustoa@hotmail.com
Over the last decade, various methods for producing HA coatings on titanium and its alloys have been developed ${ }^{10-25}$. These include plasma spray ${ }^{10-18}$, sputtering ${ }^{19,20}$, electrophoretic deposition ${ }^{21,22}$, immersion in simulated body fluid (SBF) ${ }^{23}$, biomimetic techniques ${ }^{24}$, sol-gel procedures ${ }^{25,26}$ and laser ablation ${ }^{27}$. There are, however, some problems related to the hydroxyapatite coatings, such as poor control of the chemical composition and structure and poor coating adhesion to the substrate ${ }^{5,28-30}$. Therefore, there is still a demand for methods to produce HA with greater bioactivity and similarity to human bone combined with good mechanical properties ${ }^{31,32}$.

The absorption of nutrients and the growth of bone are improved by the presence of ions such as $\mathrm{Zn}^{+2}, \mathrm{Mg}^{+2}, \mathrm{Na}^{+}, \mathrm{CO}_{3}^{-2}$ and $\mathrm{F}$ in non-stoichiometric compounds of low crystallinity ${ }^{33-35}$. Owing to that, improvements in the biological properties and greater similarity to human bone can be achieved by the incorporation of ionic elements into synthetic $\mathrm{HA}^{36,37}$. Magnesium is the fourth most abundant ion present in the human body, where it helps to inhibit crystallization, to reduce crystal size, to decrease the proliferation and activities of osteoblast-like cells ${ }^{38-41}$. Therefore, magnesium deficiency can affect bone metabolism and growth, reducing osteoplastic activity and resulting in fragile bones ${ }^{42-46}$.

Plasma Electrolytic Oxidation (PEO) combines the effects of conventional electrolysis with micro-arc discharges that appear on the sample surface. When the voltage applied 
between two electrodes immersed in electrolytic solutions exceeds several hundred volts, the dielectric barrier of the oxide coating produced on the metal surface at the anode is broken down mostly by impact ionizations. Consequently, many high energy micro-arcs able to melt the oxide coating arise on the surface of the sample. In this condition, chemical elements present in the electrolytic solution can be incorporated into the coating. Also, the high thermal energy from the micro-arcs can produce ceramic coatings with complex structures. This method has been successfully used to produce ceramic coatings on light weight metals such as $\mathrm{Ti}, \mathrm{Al}, \mathrm{Nb}$, Ta and $\mathrm{Mg}^{47}$.

Recent studies have shown that HA can be produced by PEO of titanium and its alloys. Usually, however, long process times ( $>20 \mathrm{~min}$ ) or two-step procedures are required and the HA produced is of low crystallinity ${ }^{48,49}$. In titanium oxidation using PEO other structures such as anatase, rutile, and phosphates are also produced. Results of X-ray diffraction (XRD) studies have shown that the proportion of HA is generally low, i.e., anatase and rutile phases are predominant ${ }^{50}$. To our best knowledge there were no studies of the production of HA by PEO with $\mathrm{Mg}$ incorporation into the coating for improved bioactivity of the synthetic HA. Thus, this study aims to produce a coating on Grade 4 titanium with a high concentration of Mg-doped HA with very short treatment time.

\section{Experimental description}

The HA coatings were deposited on grade 4 titanium disks $8 \mathrm{~mm}$ in diameter and $2 \mathrm{~mm}$ thick. After machining and polishing, the substrates were ultrasonically cleaned and stored. Figure 1 shows schematically the treatment system. The treatments have been performed using a two liter stainless steel tank, enclosed in a cooling system that keeps the temperature of the solution constant. The substrate was connected to the positive terminal of a pulsed bipolar voltage supply and the tank itself served as the cathode. The electrolytic solution used for the treatment was prepared by diluting $0.2 \mathrm{M}$ of calcium acetate and $0.02 \mathrm{M}$ of sodium glycerophosphate in deionized water. The variable process parameter was the amount $\mathrm{C}_{\mathrm{M}}$ of magnesium acetate $(\mathrm{MgA})$ added in concentrations of $0.0,0.02,0.04,0.06$ and $0.08 \mathrm{M}$ to the electrolytic solution. The samples have been biased with positive pulses of $480 \mathrm{~V}$ with frequency and duty cycle of $100 \mathrm{~Hz}$ and $60 \%$, respectively. The substrates were treated for $120 \mathrm{~s}$ in the potentiostatic mode. After PEO treatment, the samples were cleaned with distilled water and dried.

A previous study by the authors ${ }^{51}$ concluded that a treatment time of $120 \mathrm{~s}$ was sufficient to produce a coating with a high HA content. Therefore, based on that study, all the other process parameters were maintained; only a different amount of MgA in the electrolytic solution was used.

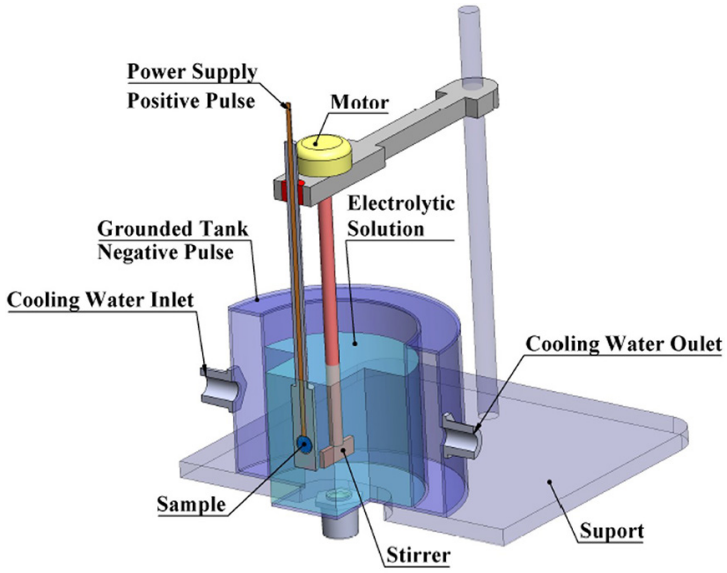

Figure 1. Schematic representation of the treatment cell.

After metallographic preparation of cross-sectioned samples, coating thickness was measured using scanning electron microscopy (SEM). Roughness was investigated using profilometry and surface morphology was examined by SEM.

The chemical composition of the samples was analyzed using Rutherford backscattering spectrometry (RBS). $\mathrm{A} \mathrm{He}^{+}$ beam, from a Pelletron-tandem accelerator produced by National Electrostatic Corporation (NEC) model 5SDH, was directed onto the samples in a vacuum chamber at $7^{\circ}$ incidence and $170^{\circ}$ scattering angles. The energy of the ions was $3.29 \mathrm{MeV}$ and the beam charge was $10 \mu \mathrm{C}$. Chemical composition and elemental depth profiles were determined by computer simulations using RUMP ${ }^{52}$ and SIMNRA ${ }^{53}$ softwares.

Analysis of the coating crystalline structure was based on X-ray diffraction data obtained using a Panalytical X-Pert Powder diffractometer in theta-2 theta geometry, which employed $\mathrm{Cu}-\mathrm{K}_{\alpha}$ radiation $(\lambda=1.54 \AA$ ). Data acquisition was performed at diffraction angles of between 20 and $60^{\circ}$, using a step-size of $0.02^{\circ}$ at $5 \mathrm{~s}$ per step. The Rietveld Refinement technique was employed to determinate the proportion of each phase as well as hydroxyapatite cell parameters. The refinement was performed using X'Pert HighScorePlus software with the structural model (ISCD database) listed in Table 1 . The quantity of each phase was calculated, but the cell parameters were determined only for the HA phase, the main object of study in this research. The electric current through the electrolytic cell was measured with a digital amperimeter every $2 \mathrm{~s}$ during the treatment. Three measurements were performed for each treatment condition.

\section{Results and Discussion}

\subsection{Current density characteristics.}

Figure 2 (a) shows the current density during the treatment and the average current density after $7 \mathrm{~s}$ of treatment, when the voltage reached $480 \mathrm{~V}$, is presented in Figure 2 (b). 
Table 1. Structural model (ISCD database) of the possible phases present in the PEO coating.

\begin{tabular}{lcc}
\hline Phase & Formula & ICSD code \\
\hline Anatase & $\mathrm{TiO}_{2}$ & 200392 \\
Rutile & $\mathrm{TiO}_{2}$ & 36413 \\
Titanium & $\mathrm{Ti}$ & 43614 \\
Calcium Phosphate & $\mathrm{Ca}_{5} \mathrm{P}_{8}$ & 74854 \\
Hydroxyapatite & $\mathrm{Ca}_{5}\left(\mathrm{PO}_{4}\right)_{3}(\mathrm{HO})$ & 203027 \\
Magnesium Phosphide & $\mathrm{Mg}_{3} \mathrm{P}_{2}$ & 24489 \\
\hline
\end{tabular}
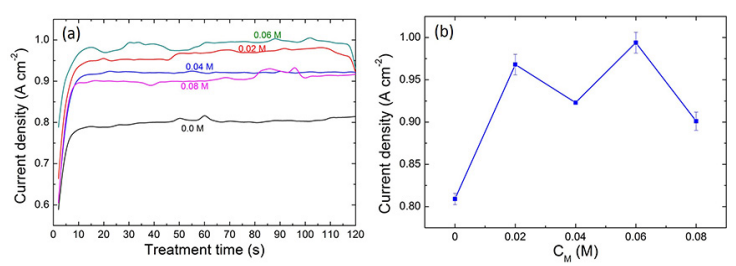

Figure 2. (a) Current density as a function of treatment time and (b) average current as a function of $\mathrm{C}_{\mathrm{M}}$.

In a general way, the addition of $\mathrm{MgA}$ to the electrolytic solutions increased the current density due to the increment of ion densities in solution. The maximum value was observed for treatments with $\mathrm{C}_{\mathrm{M}}=0.06 \mathrm{M}$. The current density in these treatment conditions was $0.99( \pm 0.012) \mathrm{A} \mathrm{cm}^{-2}$, which is $24 \%$ higher than the current density measured during treatments with $\mathrm{C}_{\mathrm{M}}=0.0 \mathrm{M}$.

Inspection of Figure 2 (b) reveals some variations in the current density, which were caused by instabilities generated by micro-arc discharges produced when the ion density was increased. The amount of MgA increased linearly but the microarcs occur in thermodynamic non-equilibrium and the electrolysis does not occur according to the usual electrochemical laws. Consequently, detailed explanations of the observed variations in the current densities are not available.

\subsection{Thickness and roughness}

The coating thicknesses were measured from MEV images of sample cross-sections prepared by metallography. Averages and standard deviations determined from measurements of the thicknesses of three samples are given. Figures 3 (left and right) show the thicknesses as a functions of $\mathrm{C}_{\mathrm{M}}$ and typical cross-sections of samples treated by PEO. The addition of magnesium acetate to the electrolytic solutions did not change significantly the coating thickness. Samples treated in solutions with $\mathrm{C}_{\mathrm{M}}$ up to $0.06 \mathrm{M}$ had thicknesses of around $10 \mu \mathrm{m}$ but samples treated at a $\mathrm{C}_{\mathrm{M}}$ of $0.08 \mathrm{M}$ had thicknesses of around $8.0 \mu \mathrm{m}$. It was also was observed that dispersion of the thickness measurements decreases when the $\mathrm{C}_{\mathrm{M}}$ was $0.06 \mathrm{M}$. Therefore, the results show that this condition $\left(\mathrm{C}_{\mathrm{M}}=0.06 \mathrm{M}\right)$ produced a more uniform coating because the process combined the best parameters of current density, voltage, composition of the electrolytic solution and treatment time.
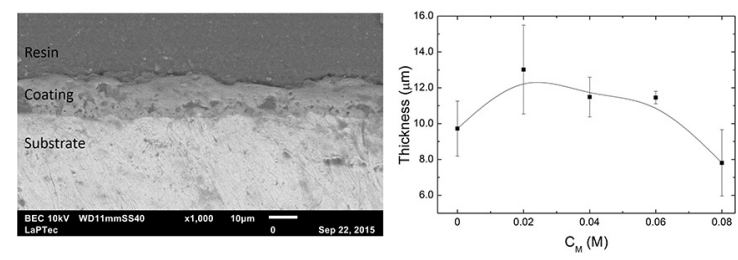

Figure 3. (left) SEM micrograph of a typical cross section of a samples treated with $\mathrm{C}_{\mathrm{M}}=0.06 \mathrm{M}$. (right) Thickness of the coatings as a function of $\mathrm{C}_{\mathrm{M}}$.

As it can be noticed in Figure 4, which shows the Ra roughness as a function of $\mathrm{C}_{\mathrm{M}}$, the roughness decreases with the increasing of $\mathrm{C}_{\mathrm{M}}$ up to $0.06 \mathrm{M}$ and then grows to reach $6.5 \pm 1.17 \mu \mathrm{m}$ when $\mathrm{C}_{\mathrm{M}}=0.08 \mathrm{M}$. This result reflects the modification of the intensities of the micro-arc as the proportion of magnesium acetate is modified.

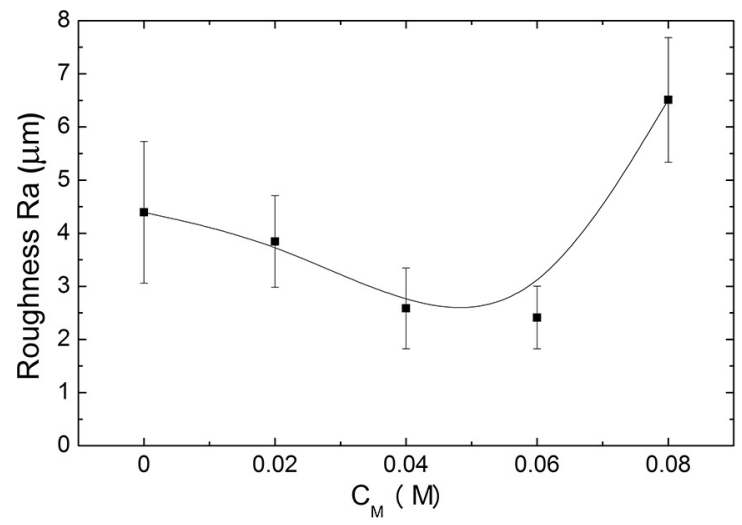

Figure 4. Roughness of titanium samples treated by PEO at different $\mathrm{C}_{\mathrm{M}}$.

\subsection{Coating Morphology}

Figure 5 presents SEM micrographs of surfaces produced in solutions with various $\mathrm{C}_{\mathrm{M}}$. It can be pointed out the presence of clusters of granular structures on the surface of all the samples produced with $\mathrm{C}_{\mathrm{M}}<0.08 \mathrm{M}$. As previously reported ${ }^{53}$, such structures are mostly composed of hydroxyapatite. Therefore, the decrease of the density of such clusters in Figure 5 suggests that the higher $\mathrm{C}_{\mathrm{M}}$ the lower the proportion of HA.

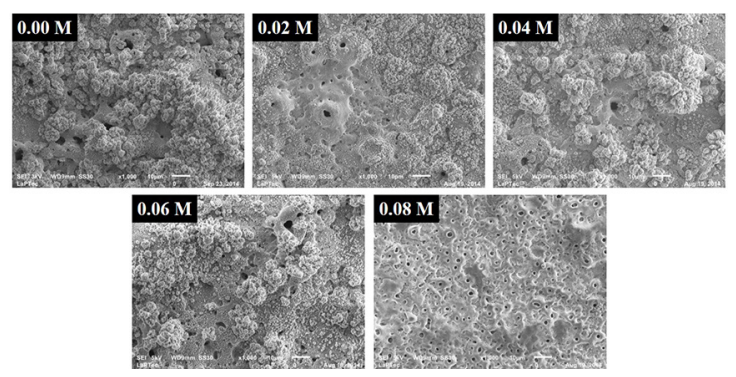

Figure 5. SEM micrographs of titanium samples treated by PEO with different $C_{M}$ concentrations. 


\subsection{Chemical compositions}

As previously noted the samples present porous irregular surfaces. As can be observed in Figure 6, which shows typical simulated and experimental RBS spectra, such rough morphology makes rather difficult the theoretical adjustment of the measured RBS spectra. Therefore, to ensure a good agreement between theoretical and experimental values, the simulations were restricted to the outermost $100 \mathrm{~nm}$ thick layer of all the samples. It is important to mention that the complexities of the simulations imposed by the irregular surface introduced an estimated error of about $5 \%$.

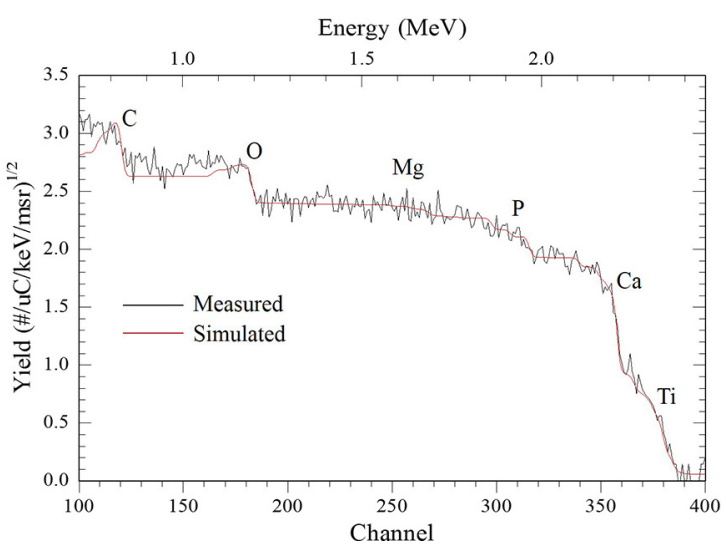

Figure 6. RBS spectrum (measured and simulated) of the sample treated by $\mathrm{PEO}$ with $\mathrm{C}_{\mathrm{M}}=0.06 \mathrm{M}$.

The average proportions of $\mathrm{Ca}, \mathrm{P}, \mathrm{Mg}$, and $\mathrm{Ti}$ in a 100 $\mathrm{nm}$ thick superficial layer can be observed in Figure 7. The proportions of carbon (nearly $32 \%$ ) and oxygen (approximately $47 \%$ ) have been omitted since they do not provide any useful information to the discussions that follow. According to the results, the addition of $\mathrm{MgA}$ to the electrolytes caused the Ca concentration to decrease from 12.2 to 8.9 at $\%$, independently of $\mathrm{C}_{\mathrm{M}}$. On the other hand, the concentration of phosphorous remained constant at 8.4 at $\%$ and decreased when $\mathrm{MgA}$ was added in proportions larger than $0.04 \mathrm{M}$ reaching $1.2 \mathrm{at} \%$ when $\mathrm{C}_{\mathrm{M}}=0.08 \mathrm{M}$. This strong decrease can be attributed to the low boiling point of $\mathrm{P}(553.6 \mathrm{~K})$, which can easily evaporate from sample surface. It has been observed the intensification of the light emitted by the micro-arcs as magnesium acetate is added to the solution. This observation associated to the higher current observed in Figure 2 indicates the enhancement of the energy transferred to the sample when MgA is added to the solution, which may cause the heating of the coating. The heating near the surface of the sample makes impedes the deposition of low melting point elements and also increases the diffusion of species to inner coating regions. Both mechanisms contribute to the observed depletion of phosphorous. In addition, the $\mathrm{Mg}$ concentration in the coating increased with the increasing of the proportion of magnesium acetate added to the solution,

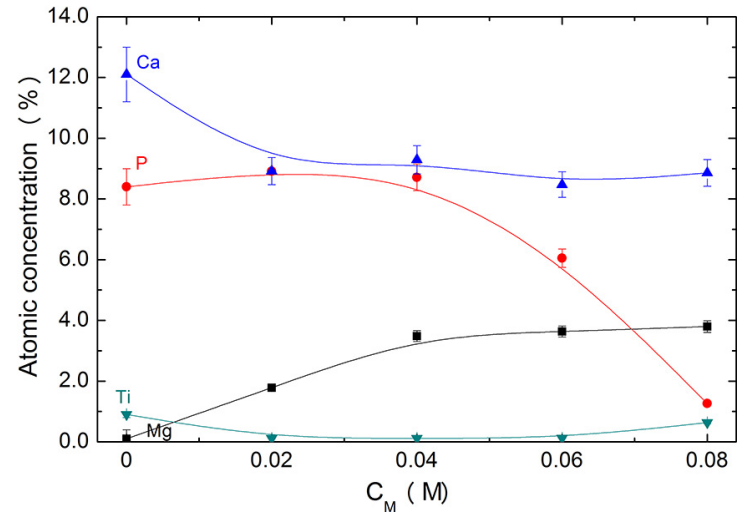

Figure 7. Average atomic proportion of elements in samples treated with different $\mathrm{C}_{\mathrm{M}}$ determined by RBS in a $100 \mathrm{~nm}$ thick superficial layer.

reaching about 3.6 at $\%$ on samples treated with $\mathrm{C}_{\mathrm{M}}=0.08$ M. Less than $1.0 \%$ of titanium has been detected in all the samples indicating that the electrophoretic deposition rather than the re-deposition of the quenched metal after melting by the micro-arc is the predominant mechanism of coating growth. Accordingly to the RBS analyses, the surfaces produced in this work are very promising for implants since they are mostly composed by $\mathrm{Ca}, \mathrm{P}$, and $\mathrm{Mg}$.

X-ray energy dispersive spectroscopy (EDS) has been employed to evaluate the coating composition in bulk regions deeper that those probed by RBS. As can be seen in Figure 8 the concentrations are significantly different from those determine near the surface. In disagreement with what is observed near the surface, the average concentrations of $\mathrm{Ca}$, $\mathrm{P}$ and $\mathrm{Ti}$ in the bulk are nearly independent of the amount of magnesium acetate added up to $\mathrm{C}_{\mathrm{M}}=0.04 \mathrm{M}$. Larger $\mathrm{C}_{\mathrm{M}}$ caused the proportions of $\mathrm{Ca}$ and $\mathrm{P}$ to decrease. When $\mathrm{CM}=$ $0.08 \mathrm{M}$ the proportion of $\mathrm{Ca}$ is $35 \%$ smaller than that measured without the addition of $\mathrm{Mg}$ acetate while the proportion of titanium increases fourfold with the same variation of $\mathrm{C}_{\mathrm{M}}$. It is interesting to mention that the proportions of calcium and phosphorous in all the conditions are roughly the same as was detected by RBS on the superficial layer of the samples produced without the addition of magnesium. This observation corroborates the supposition of the enhancement of the diffusion of species to deeper regions as a consequence of the increase of the heating caused by larger currents when the amount of $\mathrm{MgA}$ in the solution is increased. Moreover, larger current densities can produce micro-arcs intense enough to reach the substrate beneath the coating resulting in the ejection of molten titanium towards the liquid. The quenching of the metal by the electrolyte explains the high amount of Ti in the bulk of coatings as thick as $8 \mu \mathrm{m}$.

\subsection{X-ray Diffraction and Rietveld Refinement.}

Figure 9 shows X-ray diffraction spectra of the coatings produced with various $\mathrm{C}_{\mathrm{M}}$. From this figure it is possible 


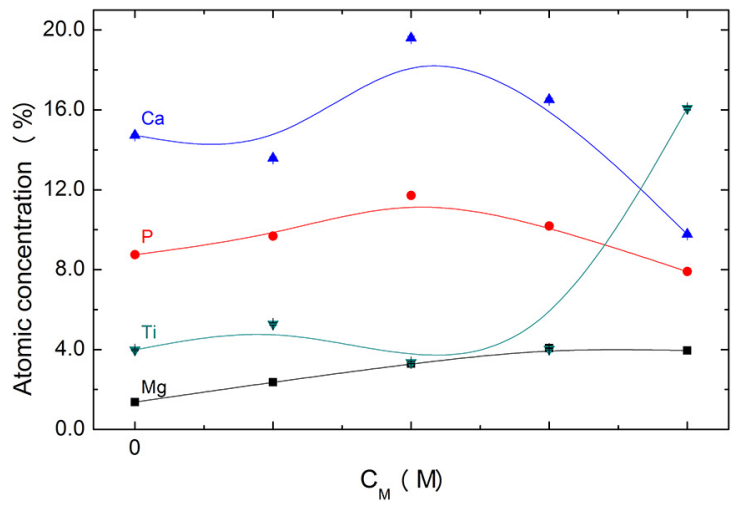

Figure 8. Atomic proportions determined by EDS in the bulk of samples treated with different $\mathrm{C}_{\mathrm{M}}$.

to observe that the treatments resulted in the formation of anatase, rutile, crystalline calcium phosphate, magnesium phosphides, and hydroxyapatite. The diffractograms also reveal the modification of the crystalline structure of the coatings as the proportion of magnesium acetate is increased. It is possible to conclude that the higher $\mathrm{C}_{\mathrm{M}}$, the smaller the peaks related to hydroxyapatite as becomes evident if one notes that diffractogram of the coating grown with $\mathrm{C}_{\mathrm{M}}=$ $0.08 \mathrm{M}$ contains only the peaks produced by anatase, rutile and metallic titanium.

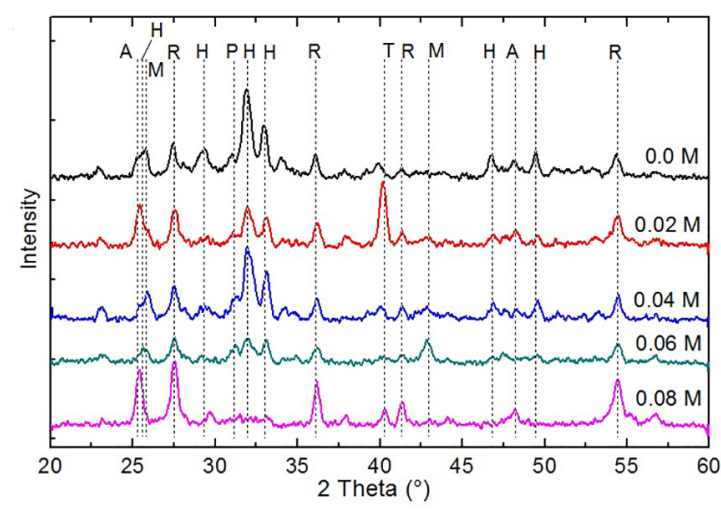

Figure 9. XRD patterns of coatings produced by $\mathrm{PEO}$ with different $\mathrm{C}_{\mathrm{M}}$, where the letters stand for: $\mathrm{H}$ - Hydroxyapatite; $\mathrm{P}$ - Calcium Phosphate, R - Rutile, M - Magnesium phosphide, A - Anatase, and $\mathrm{T}$ - titanium.

The phase composition of the samples can be better evaluated from the results of Rietveld refinement presented in Figure 10. The coating produced without the addition of $\mathrm{MgA}$ is composed by $83.5 \% \mathrm{HA}, 15,9 \%$ rutile and $0.9 \%$ calcium phosphate. Samples treated with $\mathrm{C}_{\mathrm{M}}=0.02,0.04$, and $0.06 \mathrm{M}$ are composed of around $50 \%$ hydroxyapatite. The reduction in the amount of HA can be attributed to the greater incorporation of $\mathrm{Mg}$ and the reduction of the proportion of phosphorous in the coatings, as shown in Figure 8 . In addition, the same amount of $\mathrm{P}$ was bound as magnesium phosphide $\left(\mathrm{Mg}_{3} \mathrm{P}_{2}\right)$.

The greatest amount of magnesium phosphide was observed in samples produced in electrolytic solutions with

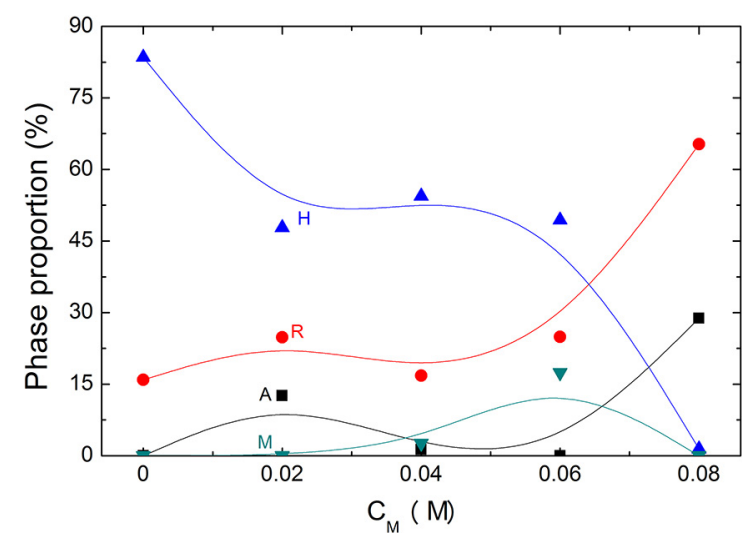

Figure 10. Phases proportion calculated by Rietveld refinement of samples treated by PEO as a function of $\mathrm{C}_{\mathrm{M}}$. The letters stand for: $\mathrm{H}$ - Hydroxyapatite, R - Rutile, M - Magnesium phosphide, and A - Anatase

$\mathrm{C}_{\mathrm{M}}=0.06 \mathrm{M}$. Therefore, this condition produced an ideal coating for biological applications because the composition of crystalline phases combines significant amounts of hydroxyapatite, magnesium phosphide and $\mathrm{TiO}_{2}$ (rutile). On the other hand, the samples produced with $\mathrm{C}_{\mathrm{M}}=0.08$ $\mathrm{M}$ were predominately composed by titanium (4.5\%) and titanium dioxide $(65.3 \%$ rutile, $28.8 \%$ anatase). No HA was formed under that condition because of the deficiency of phosphorous.

Some authors ${ }^{54,55}$ have reported that $\mathrm{Mg}^{2+}$ ions can be incorporated into the crystalline structure of hydroxyapatite, replacing $\mathrm{Ca}^{2+}$ ions. The $\mathrm{Mg}^{2+}$ ions have ionic radius of 0.069 $\mathrm{nm}$ that is smaller than radius of $\mathrm{Ca}^{2+}$ ions $(0.099 \mathrm{~nm})$. Thus $\mathrm{Mg}^{2+}$ can easily replace $\mathrm{Ca}^{2+}$ in the crystalline structure. This effect can also reduce the lattice parameters $a$ and $c$ of the hexagonal crystalline structure of the HA. In the present study, it may be observed from Figure 11 that those lattice parameters did decrease when the samples were treated with $\mathrm{C}_{\mathrm{M}}=0.02 \mathrm{M}$ and $0.04 \mathrm{M}$ in comparison with samples treated without addition of $\mathrm{MgA}$ to the electrolyte. This effect is attributed to the replacement of $\mathrm{Ca}^{2+}$ by $\mathrm{Mg}^{2+}$ ions in the hydroxyapatite crystalline structure. The sample treated with $\mathrm{C}_{\mathrm{M}}=0.06 \mathrm{M}$ presents the lattice parameters closer to the lattice parameters of samples treated without addition of $\mathrm{MgA}$. The results of Rietveld refinement revealed that this coating contains $17.4 \%$ magnesium phosphide, the largest proportion of this phase found in this study. Therefore, most of the magnesium incorporated is present as magnesium phosphide, thus explaining why the hydroxyapatite crystalline structure is similar to the crystalline structure of the hydroxyapatite produced with $\mathrm{C}_{\mathrm{M}}=0$.

\section{Conclusion}

In the present work the efficacy of PEO to produce $\mathrm{Mg}$ doped HA was studied. The addition of magnesium acetate to the electrolytic solution of calcium acetate and sodium glycerophosphate allowed the production of coatings with up 


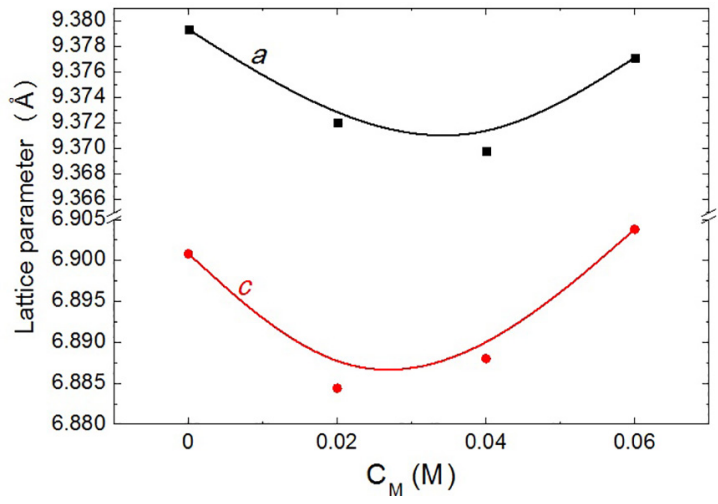

Figure 11. Hydroxyapatite lattice parameters in samples produced by $\mathrm{PEO}$ with various $\mathrm{C}_{\mathrm{M}}$.

to $50 \%$ of Mg-containing HA. Results of Rietveld refinement have shown the decrease of the lattice parameters $a$ and $c$ of HA crystalline structures in coatings produced in solutions with $\mathrm{C}_{\mathrm{M}}=0.02$ and $0.04 \mathrm{M}$. Such characteristics suggest the replacement of $\mathrm{Ca}$ by $\mathrm{Mg}$ ions in the HA structure, confirming the production of Mg-doped HA. The treatment with the electrolyte containing $0.06 \mathrm{M} \mathrm{MgA}$ was effective in producing $\mathrm{HA}$ with a crystalline structure similar to that of HA produced with $\mathrm{C}_{\mathrm{M}}=0.0 \mathrm{M}$. In that case, the coating produced contained around $17 \%$ of magnesium phosphide. In conclusion, this work demonstrated the versatility of PEO since the modification of the composition of the electrolyte allowed the adjustment of the morphology, composition, and crystalline structure of the coatings. The PEO process has been demonstrated to produce a large amount of $\mathrm{Mg}$ doped HA chemically bonded to the substrate in only $120 \mathrm{~s}$. In addition, the coating surface is porous and rough, which are important properties for biological applications.

\section{Acknowledgment}

The authors thank the Brazilian agencies FAPESP and CNPq for financial support, and Conexão for providing the titanium samples.

\section{References}

1. Albrektsson T, Brånemark PI, Hansson HA, Lindström J. Osseointegrated titanium implants. Requirements for ensuring a long-lasting, direct bone-to-implant anchorage in man. Acta Orthopaedica Scandinavica. 1981;52(2):155-170.

2. Long M, Rack HJ. Titanium alloys in total joint replacement-a materials science perspective. Biomaterials. 1998;19(18):16211639 .

3. Sennerby L, Thomsen P, Ericson LE. Ultrastructure of the bone-titanium interface in rabbits. Journal of Materials Science: Materials in Medicine. 1992;3(4):262-271.

4. Steflik DE, Sisk AL, Parr GR, Gardner LK, Hanes PJ, Lake FT, et al. Osteogenesis at the dental implant interface: High-voltage electron microscopic and conventional transmission electron microscopic observations. Journal of Biomedical Materials Research Part A. 1993;27(6):791-800

5. Liu F, Wang F, Shimizu T, Igarashi K, Zao L. Formation of hydroxyapatite on Ti-6Al-4V alloy by microarc oxidation and hydrothermal treatment. Surface and Coatings Technology. 2005;199(2-3):220-224.

6. Wong M, Eulenberger J, Schenk R, Hunziker E. Effect of surface topology on the osseointegration of implant materials in trabecular bone. Journal of Biomedical Materials Research. 1995;29(12):1567-1575.

7. Fatehi K, Moztarzadeh F, Solati-Hashjin M, Tahriri M, Rezvannia $\mathrm{M}$, Ravarian R. In vitro biomimetic deposition of apatite on alkaline and heat treated Ti6A14V alloy surface. Bulletin of Materials Science. 2008;31:101-108.

8. Halouani R, Bernache-Assolant D, Champion E, Ababou A. Microstructure and related mechanical properties of hot pressed hydroxyapatite ceramics. Journal of Materials Science: Materials in Medicine. 1994;5(8):563-568.

9. Thomas MB, Doremus RH. Fracture strength of dense hydroxylapatite. American Ceramic Society Bulletin. 1981;60(2):258-259.

10. Vijayaraghavan TV, Bensalem A. Electrodeposition of apatite coating on pure titanium and titanium alloys. Journal of Materials Science Letters. 1994;13(24):1782-1785.

11. Weng W, Baptista JL. Preparation and Characterization of Hydroxyapatite Coatings on Ti6A14V Alloy by a Sol-Gel Method. Journal of the American Ceramic Society. 1999;82(1):27-32.

12. Nishio K, Neo M, Akiyama H, Nishiguchi S, Kim HM, Kokubo T, et al. The effect of alkali- and heat-treated titanium and apatite-formed titanium on osteoblastic differentiation of bone marrow cells. Journal of Biomedical Materials Research. 2000;52(4):652-661.

13. Wang CK, Lin JH, Ju CP, Ong HC, Chang RP. Structural characterization of pulsed laser-deposited hydroxyapatite film on titanium substrate. Biomaterials. 1997;18(20):1331-1338.

14. Yang B, Uchida M, Kim HM, Zhang X, Kokubo T. Preparation of bioactive titanium metal via anodic oxidation treatment. Biomaterials. 2004;25(6):1003-1010.

15. Lim YM, Park YJ, Yun YH, Hwang KS. Functionally graded Ti/HAP coatings on Ti-6Al-4V obtained by chemical solution deposition. Ceramics International. 2002;28(1):37-41.

16. Yang S, Man HC, Xing W, Zheng X. Adhesion strength of plasma-sprayed hydroxyapatite coatings on laser gas-nitrided pure titanium. Surface and Coatings Technology. 2009;203(2021):3116-3122.

17. Kozerski S, Pawlowski L, Jaworski R, Roudet F, Petit F. Two zones microstructure of suspension plasma sprayed hydroxyapatite coatings. Surface and Coatings Technology. 2010;204(9-10):1380-1387.

18. d'Haese R, Pawlowski L, Bigan M, Jaworski R, Martel M. Phase evolution of hydroxapatite coatings suspension plasma sprayed using variable parameters in simulated body fluid. Surface and Coatings Technology. 2010;204(8):1236-1246.

19. Chen S, Liu W, Huang Z, Liu X, Zhang Q, Lu X. The simulation of the electrochemical cathodic Ca-P deposition process. Materials Science and Engineering: C. 2009;29(1):108-114. 
20. Blackwood DJ, Seah KHW. Electrochemical cathodic deposition of hydroxyapatite: improvements in adhesion and crystallinity. Materials Science and Engineering: C. 2009;29(4):1233-1238.

21. Wang J, Huang C, Wan Q, Chen Y, Chao Y. Characterization of fluoridated hydroxyapatite/zirconia nano-composite coating deposited by a modified electrocodeposition technique. Surface and Coatings Technology. 2010;204(16-17):2576-2582.

22. Yang X, Zhang B, Lu J, Chen J, Zhang X, Gu Z. Biomimetic Ca-P coating on pre-calcified Ti plates by electrodeposition method. Applied Surface Science. 2010;256(9):2700-2704.

23. Long LH, Chen LD, Bai SQ, Chang J, Lin KL. Preparation of dense $\beta-\mathrm{CaSiO}_{3}$ ceramic with high mechanical strength and HAp formation ability in simulated body fluid. Journal of the European Ceramic Society. 2006;26(9):1701-1706.

24. Zhang E, Zou C, Zeng S. Preparation and characterization of silicon-substituted hydroxyapatite coating by a biomimetic process on titanium substrate. Surface and Coatings Technology. 2009;203(8):1075-1080.

25. Cheng K, Zhang S, Weng W, Zeng X. The interfacial study of sol-gel-derived fluoridated hydroxyapatite coatings. Surface and Coatings Technology. 2005;198(1-3):242-246.

26. Zhang S, Zeng X, Wang Y, Cheng K, Weng W. Adhesion strength of sol-gel derived fluoridated hydroxyapatite coatings. Surface and Coatings Technology. 2006;200(22-23):6350-6354.

27. Hu J, Wang Z, Guan T, Gao Y, Lv X, Lin X, et al. In situ synthesis and fabrication of tricalcium phosphate bioceramic coating on commercially pure titanium by laser rapid forming. Surface and Coatings Technology. 2010;204(23):3833-3837.

28. Wang BC, Chang E, Lee TM, Yang CY. Changes in phases and crystallinity of plasma-sprayed hydroxyapatite coatings under heat treatment: A quantitative study. Journal of Biomedical Materials Research. 1995;29(12):1483-1492.

29. Kangasniemi IM, Verheyen CC, van der Velde EA, de Groot $\mathrm{K}$. In vivo tensile testing of fluorapatite and hydroxylapatite plasma-sprayed coatings. Journal of Biomedical Materials Research. 1994;28(5):563-572.

30. Liu F, Wang F, Shimizu T, Igarashi K, Zhao L. Hydroxyapatite formation on oxide films containing $\mathrm{Ca}$ and $\mathrm{P}$ by hydrothermal treatment. Ceramics International. 2006;32(5):527-531.

31. Jahangir AA, Nunley RM, Mehta S, Sharan A; the Washington Health Policy Fellows. Bone graft substitutes in orthopaedic surgery. AAOS Now; 2008. Available from: <http://www. aaos.org/news/aaosnow/jan08/reimbursement2.asp $>$. Access in: $06 / 03 / 2027$.

32. Bose S, Tarafder S. Calcium phosphate ceramic systems in growth factor and drug delivery for bone tissue engineering: a review. Acta Biomaterialia. 2012;8(4):1401-1421.

33. Elliott JC. Structure and Chemistry of the Apatite and Other Calcium Orthophosphates. In: Elliot JC, ed. Studies in Inorganic Chemistry. Amsterdam: Elsevier; 1994. p. 111-189.

34. Mayer I, Featherstone JDB. Dissolution studies of Zn-containing carbonated hydroxyapatites. Journal of Crystal Growth. 2000;219(1-2):98-101.
35. Abdelkader SB, Khatetech I, Rey C, Jemal M. Synthese, caractérisation et thermochimie d'apatites calco-magnésiennes hydroxylées et fluorées. Thermochimica Acta. 2001;376(1):25-36.

36. Narasaraju TSB, Phebe DE. Some physico-chemical aspects of hydroxyapatite. Journal of Materials Science. 1996;31(1):1-21.

37. Gaines RV, Skinner HCV, Foord EF, Mason B, Rosenzweig A. Dana's New Mineralogy. Hoboken: Wiley; 1997.

38. Sun ZP, Ercan B, Evis Z, Webster TJ. Microstructural, mechanical, and osteocompatibility properties of $\mathrm{Mg} 2+/ \mathrm{F}$ - doped nanophase hydroxyapatite. Journal of Biomedical Materials Research. Part A. 2010;94(3):806-815.

39. Bigi A, Falini G, Foresti E, Ripamonti A, Gazzano M, Roveri N. Magnesium influence on hydroxyapatite crystallization. Journal of Inorganic Biochemistry. 1993;49(1):69-78.

40. TenHuisen KS, Brown PW. Effects of magnesium on the formation of calcium deficient hydroxyapatite from $\mathrm{CaHPO}_{4} \cdot 2 \mathrm{H}_{2} \mathrm{O}$ and $\mathrm{Ca}_{4}\left(\mathrm{PO}_{4}\right)_{2} \mathrm{O}$. Journal of Biomedical Materials Research. 1997;36(3):306-314

41. Le Geros RZ. Calcium phosphates in oral biology and medicine. Monographs in Oral Science. 1991;15:1-201.

42. Percival M. Bone health \& osteoporosis. Applied Nutritional Science Reports. 1999;5(4):1-6.

43. Yasukawa A, Ouchi S, Kandori K, Ishikawa T. Preparation and characterization of magnesium-calcium hydroxyapatites. Journal of Materials Chemistry. 1996;6(8):1401-1405.

44. Okazaki M. Crystallographic behavior of fluoridate hydroxyapatites containing $\mathrm{Mg}^{2+}$ and $\mathrm{CO}_{3}^{2-}$ Ions. Biomaterials. 1991;12(9):831-835.

45. Kim SR, Lee JH, Kim YT, Riu DH, Jung SJ, Lee YJ, et al. Synthesis of $\mathrm{Si}, \mathrm{Mg}$, substituted hydroxyapatites and their sintering behaviors. Biomaterials. 2003;24(8):1389-1398.

46. Rude RK, Gruber HE. Magnesium deficiency and osteoporosis: animal and human observations. The Journal of Nutritional Biochemistry. 2004;15(12):710-716.

47. Yerokhin AL, Nie X, Leyland A, Matthews A. Characterisation of oxide films produced by plasma electrolytic oxidation of a Ti-6Al-4V alloy. Surface and Coatings Technology. 2000;130(2-3):195-206.

48. Durdu S, Deniz ÖF, Kutbay I, Usta M. Characterization and formation of hydroxyapatite on Ti6Al4V coated by plasma electrolytic oxidation. Journal of Alloys and Compounds. 2013;551:422-429.

49. Ziani S, Meski S, Khireddine H. Characterization of MagnesiumDoped Hydroxyapatite Prepared by Sol-Gel Process. International Journal of Applied Ceramic Technology. 2014;11(1):83-91.

50. Durdu S, Usta M. The tribological properties of bioceramic coatings produced on Ti6Al4V alloy by plasma electrolytic oxidation. Ceramics International. 2014;40(2):3627-3635.

51. Antônio CA, Cruz NC, Rangel EC, Rangel RCC, Araujo TES, Durrant SF, et al. Hydroxyapatite coating deposited on grade 4 Titanium by Plasma Electrolytic Oxidation. Materials Research. 2014;17(6):1427-1433.

52. Doolittle LR. Algorithms for the rapid simulation of Rutherford backscattering spectra. Nuclear Instruments and Methods in 
Physics Research Section B: Beam Interactions with Materials and Atoms. 1985;9(3):344-351.

53. Markina E, Mayer M, Lee HT. Measurement of He and H depth profiles in tungsten using ERDA with medium heavy ion beams. Nuclear Instruments and Methods in Physics Research Section B: Beam Interactions with Materials and Atoms. 2001;269(24):3094-3097.
54. Okazaki M, LeGeros RZ. Crystallographic and chemical properties of Mg-containing apatites before and after suspension in solutions. Magnesium Research. 1992;5(2):103-108.

55. Landi E, Tampieri A, Mattioli-Belmonte M, Celotti C, Sandri $\mathrm{M}$, Gigante $\mathrm{A}$, et al. Biomimetic $\mathrm{Mg}$-and $\mathrm{Mg}, \mathrm{CO}_{3}$-substituted hydroxyapatites: synthesis characterization and in vitro behavior. Journal of the European Ceramic Society. 2006;26(13):2593-2601. 